\title{
VALIDATION OF THE ABSOLUTE HEIGHT ACCURACY OF TANDEM-X DEM FOR MODERATE TERRAIN
}

\author{
B. Wessel ${ }^{\mathrm{a}}$, A. Gruber ${ }^{\mathrm{a}}$, M. Huber ${ }^{\mathrm{a}}$, M. Breunig ${ }^{\mathrm{a}}$, S. Wagenbrenner ${ }^{b}$, \\ A. Wendleder ${ }^{\mathrm{a}}$, A. Roth $^{\mathrm{a}}$ \\ ${ }^{\mathrm{a}}$ German Aerospace Center (DLR), Oberpfaffenhofen, 82234 Wessling, Germany, \\ [Birgit.Wessel@dlr.de] \\ ${ }^{\mathrm{b}}$ Company for Remote Sensing and Environmental Research, Kohlsteiner Str. 5, 81243 Munich
}

\begin{abstract}
In September 2013 the production of TanDEM-X digital elevation model (DEM) started. As the data acquisition for difficult terrain lasted until April 2014, final DEM production started for flat to moderate terrain regions where two final coverages surfice. This paper focuses on a first validation of moderate terrain to prove the absolute height accuracy. In a detailed comparison three DEM tiles from different continents are chosen to validate the TanDEM-X DEM by computing differences to GPS tracks, ICESat validation points, and SRTM. On a global scale all TanDEM-X DEMs produced so far are compared with ICESat and GPS tracks. Both validations presented here for the first time indicate that the absolute height error for moderate terrain for TanDEM-X is below $2 \mathrm{~m}$ and therefore much better than the specified 10m/LE90.
\end{abstract}

Index Terms - TanDEM-X DEM, validation, accuracy, absolute height error, ICESat, GPS

\section{INTRODUCTION}

Within the TanDEM-X mission [1] the whole globe is measured by the two SAR satellites TerraSAR-X and TanDEM-X. Careful calibration of the SAR system and baseline errors was conducted. Remaining systematic errors in the order of some few meters of the individual acquisitions (so-called data takes) are estimated jointly within a block least-squares adjustment (so-called DEM calibration). The adjustment relies on using the elevation of tie-points in the overlapping regions of the interferometric DEMs and the assessment of ground control points [2]. The height offset to WGS84 is estimated by introducing absolute height reference data provided by ICESat data [3].

This paper presents two types of validation: One detailed validation based on three world-wide distributed TanDEM$X$ DEM examples for moderate terrain. We compute differences to GPS, ICESat validation points, and SRTM (absolute accuracy). One global validation with differences to GPS and ICESat as mean measures per DEM tile to prove the absolute height accuracy globally.

\section{TEST AND REFERENCE DATA}

For the accuracy assessment over moderate terrain exemplarily three DEM tiles out of the final DEM collection are chosen: Canada Saskatchewan/Manitoba (flat, agriculture land), Russia, near Kursk (grassland, agriculture land), Australia (hilly, arid area). For validation three reference data sets are used: kinematic GPS tracks, ICESat data and SRTM. The test sites are chosen in a way that a GPS track is crossing through the tile. In particular for the validation of the TanDEM-X DEM world-wide approximately $50.000 \mathrm{~km}$ of kinematic GPS tracks were measured. These tracks are specified with an accuracy of $<1.0 \mathrm{~m}$ [4] and are automatically used in the DEM Mosaicking and Calibration Processor for DEM tile quality inspection. Secondly, ICESat points are used for local and global validation. The ICESat data have undergone a quality assessment prior to their use [2]. As only a minor part of ICESat points serve as ground control points the majority of the assessed points can be used as validation points [3]. Thirdly, as raster data set SRTM C-Band is used. The SRTM-C Band data and TanDEM-X DEM correspond both to digital surface models (DSM), describing a height near the canopy surface and both contain buildings.

\section{ACCURACY ASSESSMENT}

\subsection{Detailed validation for three test sites}

Figure 1 shows in its first row the analysed, color shaded TanDEM-X DEMs. The height range of the Canada test site is $400 \mathrm{~m}$ (from $313 \mathrm{~m}$ to $713 \mathrm{~m}$ ), in Australia the terrain ranges between $-259 \mathrm{~m}$ and $943 \mathrm{~m}$ and in Russia the range is $200 \mathrm{~m}$ from $109 \mathrm{~m}$ to $308 \mathrm{~m}$. Note that the different size of the quicklooks comes from different longitude resolutions, at $50^{\circ}$ latitude the longitude pixel spacing changes from 0.4 arcsec to 0.6 arcsec for Canada and Russia. 


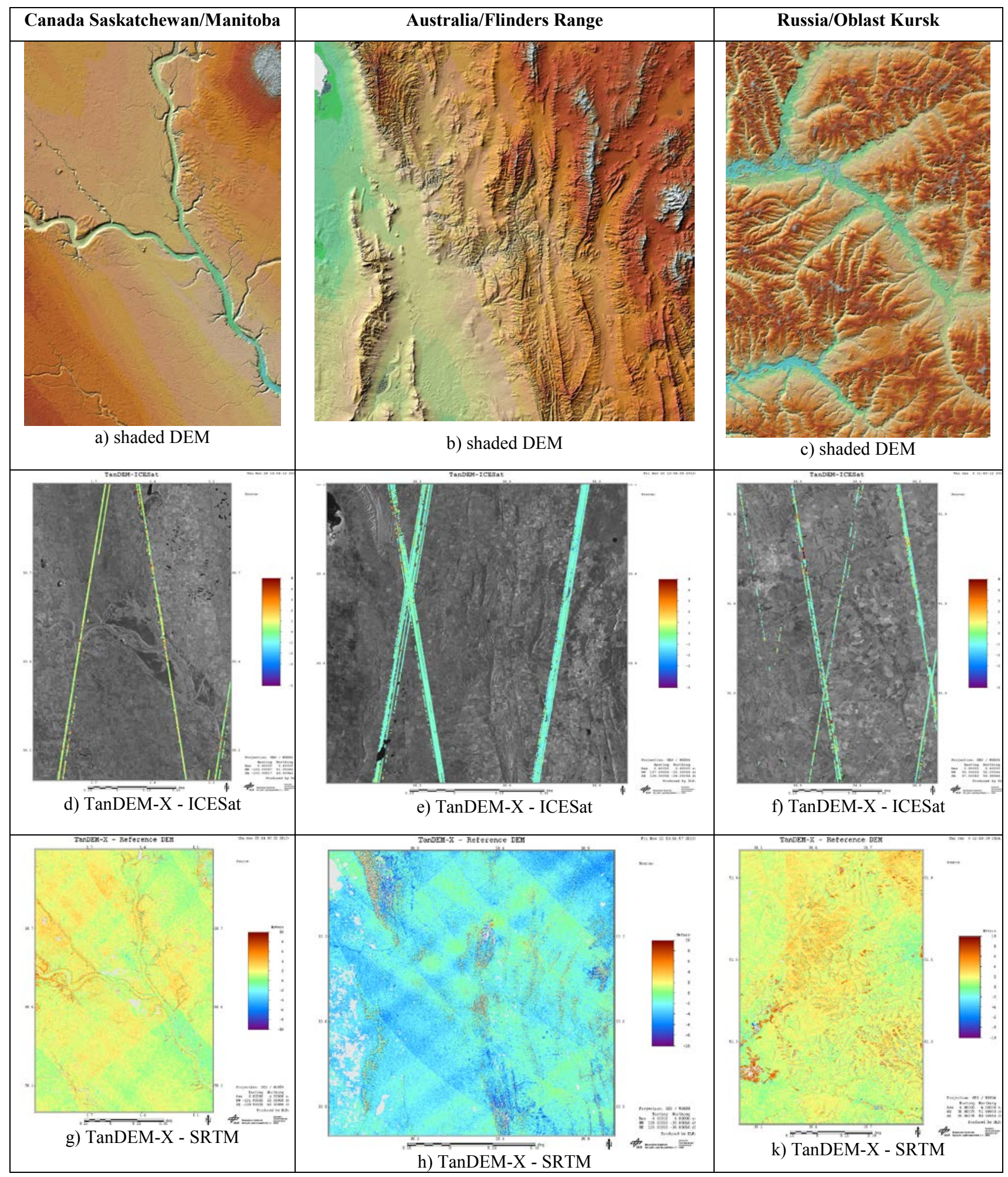

Figure 1: TanDEM-X DEM test sites 1. row shaded DEMs: a) N50W102 Saskatchewan/Manitoba,Canada b) S34E138 FlindersRange, Australia c) N51E036 Kursk, Russia, 2. row mean amplitude overlayed with the difference TanDEM-X DEM - ICESat validation points, 3. difference plot TanDEM-X DEM versus SRTM; color bar scaling +/- 5m for ICESat and +/- 10m for SRTM. 
TABLE I. Statistical parameters of the difference between TanDEM-X DEM tiles and validation data: GPS, ICESat validation points and SRTM

\begin{tabular}{|l|l|l|l|l|l|}
\hline Reference & $\begin{array}{l}\text { Mean } \\
{[\mathbf{m}]}\end{array}$ & $\begin{array}{l}\text { Std.dev } \\
{[\mathbf{m}]}\end{array}$ & $\begin{array}{l}\text { Min } \\
{[\mathbf{m}]}\end{array}$ & $\begin{array}{l}\text { Max } \\
{[\mathbf{m}]}\end{array}$ & \#points \\
\hline \hline N50W102 & \multicolumn{5}{|l|}{ Canada Saskatchewan/Manitoba } \\
\hline GPS & $\mathbf{0 . 2 0}$ & $\mathbf{0 . 4 7}$ & -2.01 & 2.20 & 20505 \\
\hline ICESat & $\mathbf{1 . 2 2}$ & $\mathbf{1 . 8 5}$ & -87.11 & 16.52 & 7114 \\
\hline SRTM & $\mathbf{2 . 3 1}$ & $\mathbf{1 . 4 2}$ & -19.41 & 41.49 & all \\
\hline \hline S34E138 & Australia, Flinders Range \\
\hline GPS & $\mathbf{- 0 . 6 7}$ & $\mathbf{0 . 7 8}$ & -11.96 & 6.89 & 22204 \\
\hline ICESat & $\mathbf{- 0 . 2 3}$ & $\mathbf{0 . 9 0}$ & -51.62 & 23.89 & 13591 \\
\hline SRTM & $\mathbf{- 1 . 9 6}$ & $\mathbf{2 . 1 1}$ & -81.97 & 38.19 & all \\
\hline \hline N51E036 & Russia, Oblast Kursk \\
\hline GPS & $\mathbf{- 0 . 0 4}$ & $\mathbf{1 . 2 3}$ & -4.27 & 17.09 & 30678 \\
\hline ICESat & $\mathbf{0 . 2 8}$ & $\mathbf{2 . 5 3}$ & -65.02 & 28.26 & 5698 \\
\hline SRTM & $\mathbf{2 . 7 4}$ & $\mathbf{2 . 0 8}$ & -22.59 & 20.22 & all \\
\hline
\end{tabular}

In the second row, Figure 1d)-1f) colored differences of TanDEM-X to ICESat validation points are plotted. The calculated measures are summarized in Table I. The mean of ICESat is just some decimeters for the Australian and Russian test site. The standard deviation for the Australian test site is lowest with $0.9 \mathrm{~m}$. Here, the arid region plays a role: for both ICESat and TanDEM-X the surface is very smooth. For more vegetated areas a standard deviation of around $2 \mathrm{~m}$ can be observed. The higher standard deviation of the mean ICESat validation points for the Canadian test site seems typical for special forested areas and will be further discussed as a global phenomenon in section 3.2.

The mean difference of the GPS points to the TanDEM-X DEM ranges from $-0.04 \mathrm{~m}$ to $-0.67 \mathrm{~m}$ with standard deviations from $0.47 \mathrm{~m}$ to $1.23 \mathrm{~m}$. These high accurate GPS data clearly state as really independent reference data a good height accuracy of TanDEM-X. According to the requirement the 90 percent height error (LE90) will be separately calculated for flat and steep terrain in further studies.

For an area-based analysis the differences to SRTM C-Band show some interesting details (see Figure 1g) $-\mathrm{k}$ )). First of all the SRTM acquisition stripes can be easily seen by the difference plots to TanDEM-X, especially for the Canadian and the Australian test site. These deviations are originated by the SRTM boom variations. In the Russian test site some small areas with height discrepancies up to $10 \mathrm{~m}$ occur. In a visual comparison with the TanDEM-X DEM and Google Earth overlay it can be shown that these differences occur at forested areas. In those regions TanDEM-X DEM contains acquisitions made in summer time. As SRTM was acquired in winter time (Februar 2000) and in C-Band the penetration into the canopy was much stronger than for TanDEM-X. The reflective surface TanDEM-X is representing in these cases is higher than SRTM.
TABLE II. Statistical parameters of the differences of all so far processed TanDEM-X DEM tiles with GPS and ICESat validation points

\begin{tabular}{|l|l|l|l|}
\hline Reference & $\begin{array}{l}\text { mean MEAN } \\
\text { for all tiles [m] }\end{array}$ & $\begin{array}{l}\text { Std.dev of } \\
\text { means [m] }\end{array}$ & $\begin{array}{l}\mathbf{9 0 \%} \text { of the } \\
\text { means below [m] }\end{array}$ \\
\hline \hline GPS & 0.68 & 1.90 & 1.94 \\
\hline ICESat & -0.33 & 1.11 & 1.57 \\
\hline
\end{tabular}

\subsection{Global validation for moderate terrain}

According to the DEM production progress around $20 \%$ of the amount of finally expected TanDEM-X DEM tiles has been processed. For each of these tiles the mean differences to the GPS tracks, if available, as well as the mean differences to ICESat validation points are calculated continuously and are plotted in Figure 2. According to Figure 2 the great majority of the GPS differences lies between $-2 \mathrm{~m}$ and $+2 \mathrm{~m}$ and shows a very homogeneous height level. This is also confirmed by the measures listed in Table II that claims for $90 \%$ of the DEM tiles processed so far a mean less than $1.57 \mathrm{~m}$ to GPS. Also the differences to ICESat in general lie between $-2 \mathrm{~m}$ and $2 \mathrm{~m}$. With $1.94 \mathrm{~m}$ here also $90 \%$ of the tiles have a mean less than $2 \mathrm{~m}$. This states a very good absolute height accuracy of TanDEM-X for moderate terrain.

But also some interesting details can be observed. In the forested regions in North America and Russia there are some higher mean differences for ICESat points ranging from $2 \mathrm{~m}$ to $6 \mathrm{~m}$ or even up to $10 \mathrm{~m}$, i.e. TanDEM level seems to be systematically higher than ICESat in these regions. Of course ICESat and TanDEM-X are measuring different height levels, especially over forest. For ICESat the centroid height of the returned signal is chosen whereas the X-Band SAR measures the top of the canopy. This might confirm lower heights of ICESat over forest. As a measure to select solely points on the bare earth surface the TanDEM-X DEM standard deviation is used. As a consequence on this observation the DEM standard deviation for ICESat validation points was limited from $5 \mathrm{~m}$ to $1 \mathrm{~m}$. This could limit the effect, but it is not yet fully understood.

\section{CONCLUSIONS}

In this paper we presented for the first time an assessment of the absolute vertical accuracy of the TanDEM-X DEM. The assessments based on one hand on a detailed analysis of three individual DEM tiles, on the other hand on an evaluation of global DEM tiles with respect to the reference data SRTM, ICESat validation points and GPS track data. Based on the presented results an excellent absolute height accuracy of TanDEM-X for moderate terrain below $2 \mathrm{~m}$ can be stated. Note that the DEM quality highly depends on the terrain slope and land cover. In this study our validation points for GPS and ICESat were located over flat and mostly low vegetated terrain. 


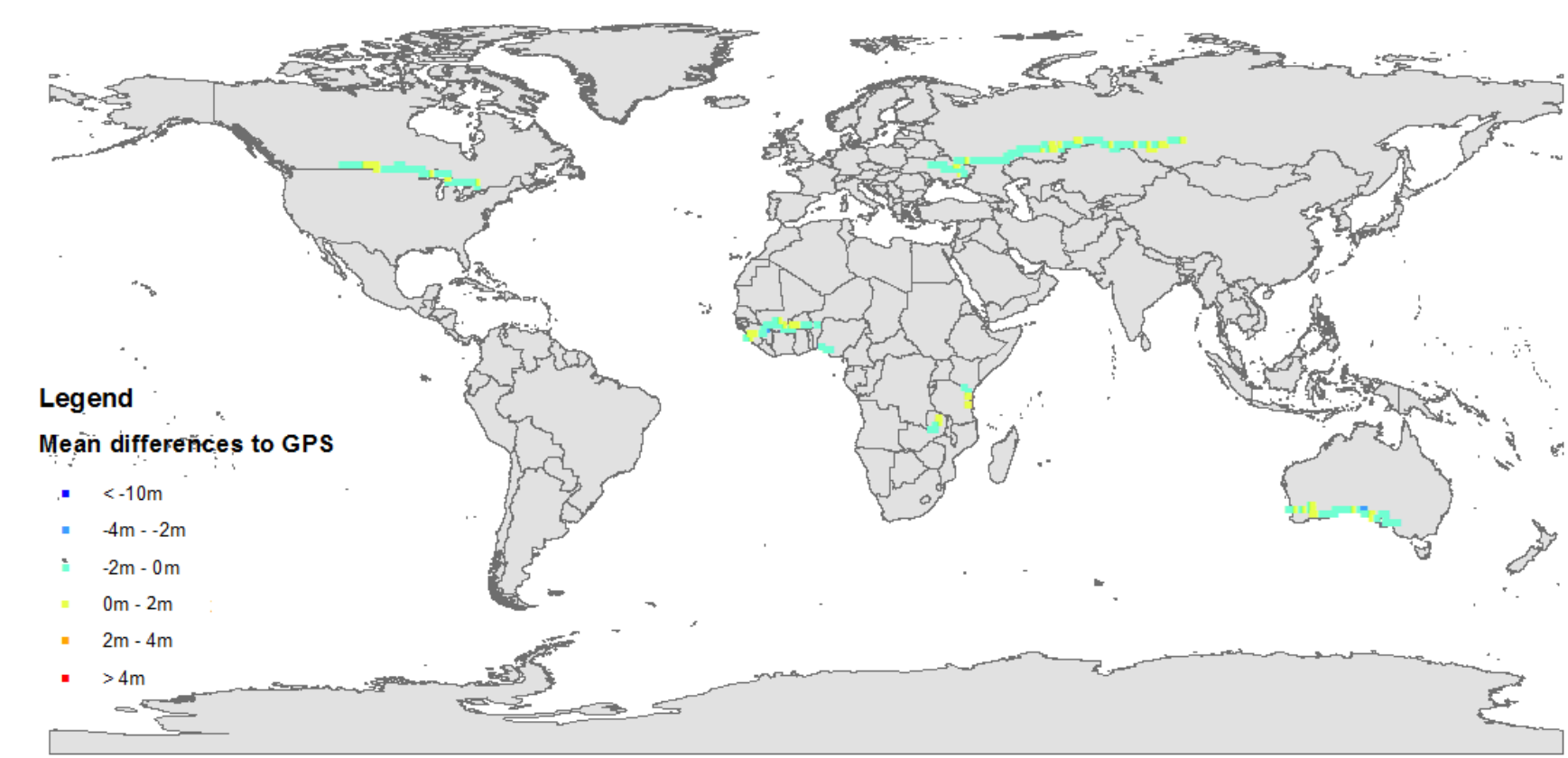

a) TanDEM-X - GPS

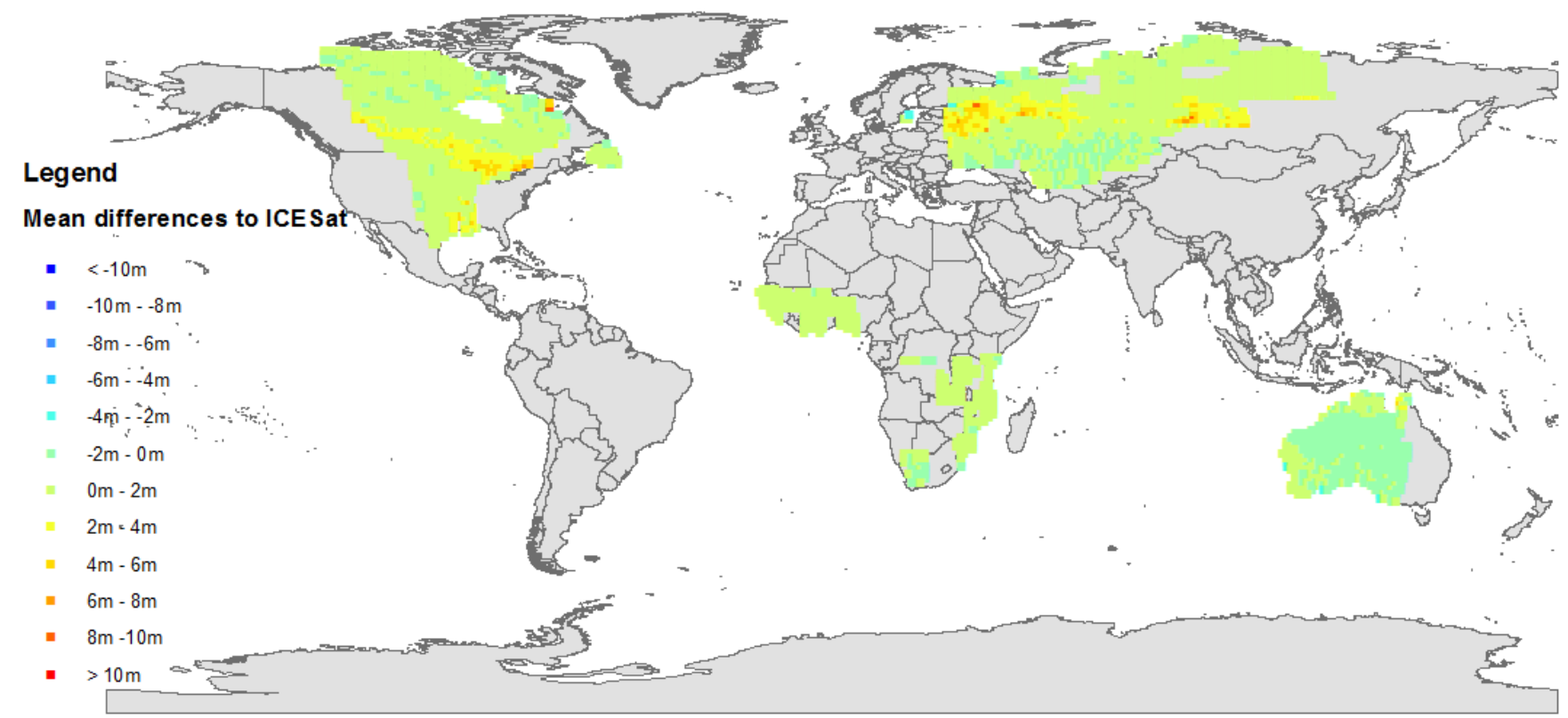

b) TanDEM-X - ICESat

Figure 2: TanDEM-X DEM processing status colored with of a) mean difference value to GPS tracks per tile and b) mean difference value to ICESat validation points per tile.

\section{REFERENCES}

[1] Moreira, A., Krieger, G., Hajnsek, I., Hounam, D., Werner, M., 2004. TanDEM-X: A TerraSAR-X Add-On Satellite for SinglePass SAR Interferometry, Proceedings of IGARSS 2004, Anchorage, USA.

[2] Gruber, Astrid und Wessel, Birgit und Huber, Martin und Roth, Achim (2012) Operational TanDEM-X DEM calibration and first validation results. ISPRS Journal of Photogrammetry and Remote
Sensing, $73, \quad$ pp. $39-49 . \quad$ DOI: http://dx.doi.org/10.1016/i.isprsjprs.2012.06.002.

[3] Huber, M., Wessel, B., Kosmann, D., Felbier, A., Schwieger, V., Habermeyer, M., Wendleder, A., Roth, A., 2009. Ensuring globally the TanDEM-X height accuracy: Analysis of the reference data sets ICESat, SRTM, and KGPS-Tracks. Proceedings of IGARSS 2009, Cape Town, South Africa.

[4] Kosmann, D., Wessel, B. Schwieger, V., 2010. Global Digital Elevation Model from TanDEM-X and the Calibration/Validation with worldwide kinematic GPS-Tracks. XXIV FIG International Congress 2010, 11. April - 16. April 2010, Sydney, Australia. 